\title{
Internal Theft Crime as an Internal Threat for National Economic Resilience in Small and Medium Manufacturing Industry Sectors
}

\author{
Faidah Mardika ${ }^{1}$, Josias Simon ${ }^{2}$ \\ \{faidah.mardika@gmail.com ${ }^{1}$, simonrbi@yahoo.com $\left.{ }^{2}\right\}$

\begin{abstract}
${ }^{1}$ Criminology Department Universitas Indonesia, School of Government and Public Policy (SGPP) Indonesia, ${ }^{2}$ Head of National Resilience Studies School of Strategic and Global Studies, Universitas Indonesia, lecturer at Criminology Department, Universitas Indonesia
\end{abstract}

\begin{abstract}
The discussion on the development and resilience of the economy, especially in the realm of the manufacturing industry has pretty much discussed external factors such as business competition, free-market conditions to marketing strategies. Unfortunately, the threat and efforts to strengthen internal managerial aspects are still rarely discussed, especially regarding the issue of preventing internal theft. Although there has not been much attention, several studies have shown data that internal theft contributes significantly to business failure. Unfortunately, crime prevention in the manufacturing industry is still hampered by its application related to personnel skills and costs. This study discusses the role of preventing internal theft against the stability of business continuity to shape national resilience in the economic field. By specifying for small and medium scale manufacturing industries, this study also analyzed the Material Handling System as an effort to prevent crime.
\end{abstract}

Keywords: Internal Theft, Economic Resilience, Crime Prevention, Manufacturing Industry

\section{Introduction}

Security becomes a necessity for everyone. Both in the scope of individuals, corporations, and countries. The security is related to the opportunity for everyone to become a victim of crime, disaster, and other risky events. Including for the industrial world. Hence, the sustainability of the industrial sector in Indonesia in the future may be influenced by the factor of security stability too. Security in this industrial sector has an important role, especially for long-term sustainability and ensures the stability of the working conditions of employees because they avoid losses. The conception of security itself is an influence of internal and external factors and is also influenced by an assessment of the situation being faced by someone. Therefore, to create a feeling or a safe condition, it is necessary to take steps to handle and prevent the physical condition as well as the security measures implemented. This is certainly done to create a safe environment and make a smaller risk of becoming a victim of crime. But unfortunately, the need for security that everyone wants is not always well realized. Now, security from the micro aspect is considered not only beneficial for individuals or institutions that implement the system but also can further contribute to national stability and resilience, one of which is in the economic field. 


\subsection{Manufacturing Industry and Indonesia Economic Resilience}

By making the manufacturing industry the subject of this research, what exactly is it and how does the manufacturing industry sector contribute to Indonesia's economic resilience?

One way to overcome the problem of developing economic conditions in developing countries, including Indonesia, is to develop the industrial sector. In the journey of Indonesia from developing countries to developed countries, the industrial sector is now getting a large focus to be developed [1]. With a large number of medium and large-scale industries in Indonesia today, the industrial sector, especially non-oil and gas, contributes to the development of the Indonesian economy. In 2012, according to data from the Ministry of Industry, the biggest source of economic growth for Indonesia came from the non-oil and gas industry sector, which amounted to $6.4 \%$ supported by consumption and increased investment. This role has made the industrial sector increasingly important. Surely, the condition of the Indonesian economy which shows this improvement must be supported and maintained so that it can take place on an ongoing basis. One of them is by creating stable conditions in the political, legal and security aspects [2].

In addition to have a role in the aspect of production productivity and export capability, the manufacturing industry also has a significant role in terms of employment. According to data from the Ministry of Industry, in 2017 the manufacturing industry sector can produce 16.3 million workers, which indicates an increase of 5\% compared to last year which was 15.54 million people. Whereas in 2018 the ability of the manufacturing industry to absorb employment again rose to 18.25 million workers. From this number, the types of industries that absorb the most labor are textile, shoes, food, and beverages.

Besides that, the large population of Indonesia has its national potential that can encourage the growth of small and medium scale manufacturing industries. Moreover, according to data from the Ministry of Industry of the Republic of Indonesia in 2015, about $80 \%$ of the industrial structure in Indonesia is small and medium scale and in particular have a significant role in national economic growth and resilience as seen from the number of industrial business units that reached 3.4 million units in 2013 and contributed as much as $90 \%$ of the total business units of the national industrial sector. This small and medium industry business unit also absorbs 9.7 million workers, equivalent to $65.4 \%$ of the total workforce in the non-oil and gas industry sector.

From the explanation above, we can see that the manufacturing industry has a significant contribution to various aspects of Indonesia. However, of course with this contribution, the manufacturing industry in Indonesia has various threats and risks that come from external and internal factors. This makes the stability of the manufacturing industry, especially those of small and medium scale, have a higher vulnerability because it must be recognized that in a small and medium scale industrial system, not all of them implement qualified supervisory management. This small and medium scale industry also has a lower ability to bear all forms of loss, including those caused by internal theft. One of the threats that becomes a problem in the world of scale manufacturing industry This is the main point of attention in this research, namely regarding efforts to improve the stability and sustainability of small and medium scale manufacturing industries through increasing the ability to identify and handle the occurrence of internal theft that occurs in the industrial environment. 


\subsection{Internal Theft at Manufacturing Industry Context}

One of the threats and risks that overshadow the business of small and medium scale manufacturing industries is internal theft committed by workers against the company's assets. The form of crime that will be investigated more deeply is theft that occurs in industry and is carried out by internal parties. In this research, the act of theft that occurs in the manufacturing process of the manufacturing industry is carried out by internal company parties or commonly referred to as Internal Theft [3]. Internal Theft is an act of theft committed by an internal party within an environmental scope. In other words, the act of theft is not carried out by strangers, but those who have involvement and access to an aspect in a structure. Thus, in a work environment, Internal Theft has the opportunity to be carried out by every employee from various management levels. Friedrich [4] states that Internal Theft is one form of occupational crime when viewed from the perpetrators and the types of actions. Most people see that employees or workers are only lower-class workers, but here it is explicitly explained that employees are everyone who is paid by another individual, group, or business, so this definition also applies to upper-class executives and managers [4]. Even top-class executive employees and managers are in the best position to be able to generate losses in the company on a large scale and also take greater responsibility for the proportion of losses suffered by the company. One form of crime by workers that often occurs is theft by employees

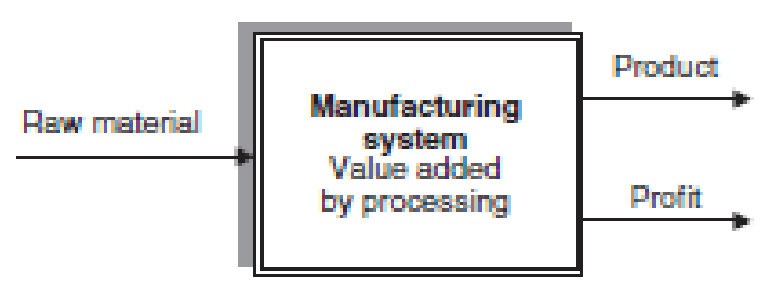

Fig. 1. A Simple Model of the Process to Increasing Value from Raw Material at Manufacturing Industry [8]

Then, how can internal theft pose its threat to the stability of the manufacturing industry? Research on theft carried out by employees has now become interesting and important to do. The University of Florida's National Retail Security Survey (NRSS) states that 4 things are the main causes of the shrinking of the company's belongings, namely employee theft, shoplifting, errors in the bookkeeping system, and fraud [5]. In these 4 lists, employee theft is considered to affect approximately $47 \%$ of cases of loss of company inventory. On a larger scale, theft by employees causes as much as $30 \%$ failure for small industries to develop [6]. Besides, losses incurred as a result of theft in the industry amounted to 40 billion dollars with almost $75 \%$ of the theft not detected [7].

From this explanation, it generally can be seen that there are still problems faced by companies related to security, although it is seen that the industrial sector has now implemented security measures in their respective industrial environments. This still leaves the company in a vulnerable situation that can be targeted by crimes, especially those committed by internal company parties. Which can happen in all aspects of the weaknesses they have in the security 
measures they have implemented. This phenomenon is certainly supported by the special access possessed by potential actors related to the position and special position that is being held [7].

The manufacturing industry has a series of processes to make tangible goods, starting from supplying raw materials using various processes, equipment, operations and manpower based on details that have been designed to be cost-effective (in a manufacturing system) to bring in revenue and profits through the distribution of sales [8]. From this definition, it can be seen that the manufacturing industry generally has a complex set of processes to turn raw materials into finished goods that have a better value from the nominal and functional points. The process is commonly referred to as a manufacturing system that has different stages in each type of industry.

Production activities in the manufacturing industry in the Manufacturing Organization and Management book, it is stated that one of the things that should be the main concern is the Material Handling process which is simply defined as all the changes that occur in materials in the manufacturing process. More specifically, the Material Handling Division of the American Society of Mechanical Engineering defines Material Handling as an art and science in the transfer, packaging, and warehousing of things in various forms [9]

Various processes that exist in Material Handling are carried out for all stages of the production process, which starts from the movement of raw materials and materials from suppliers to the factory area to the distribution of finished goods to consumers. In its operation, there are elements involved in the Material Handling process, namely humans, machines and the environment so that Material Handling is a man-machine-environment system [10]. In a paper by Shengzhao Long and Balbir S. Dhillon [11], explained that the Man-MachineEnvironment System is a study conducted to create the optimum combination of human systems, machines, and the environment. The optimum condition in question is guaranteed security, high efficiency and economy of the system. Still in the same article explained in more detail that in this system "Man" is a worker in the relevant workplace, as well as operators as well as decisionmakers. Then, "Machine" is a general term that refers to everything that is controlled and operated by workers. While the latter is the "Environment" which is the specific work location conditions where workers and tools that support their work interact. Furthermore, to be a good Material Handling system, several important points must be contained in it, namely [12] the safe and efficient transfer of materials to the desired place, the timely transfer of material, providing material based on accordance with the many required, material warehousing with minimal space, low-cost solutions to materials handling activities. 


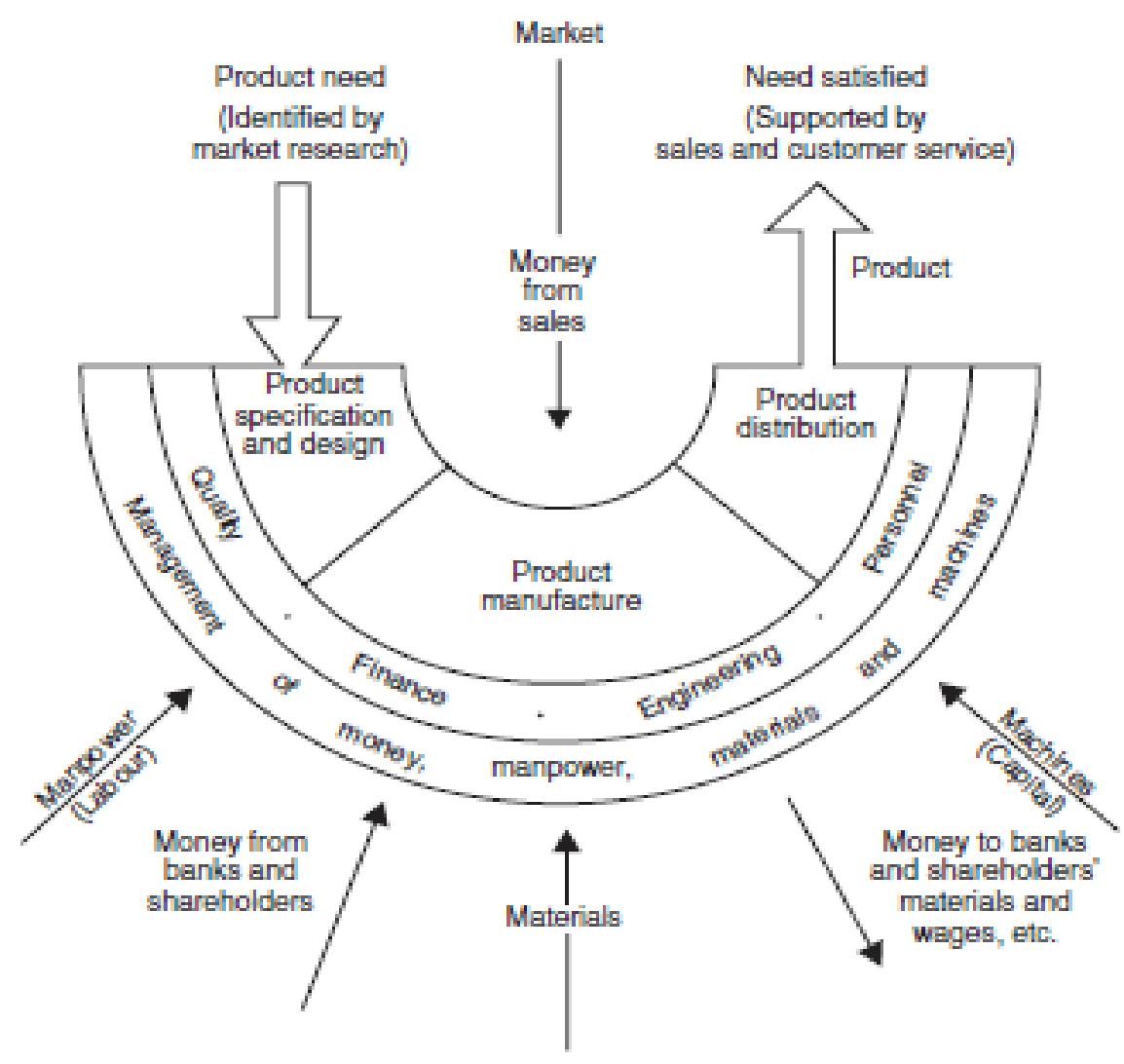

Fig. 2. Manufacturing System in General [8]

Then, how can material handling and crime prevention could be related? One theory that explains how crime can occur in one area is Problem Triangle Analysis or Crime Triangle Analysis. On Figure 3, stated that the crime triangle developed by Eck that one of the efforts that can be done to reduce the possibility of crime is to conduct surveillance by the controller of the 3 elements of crime, namely the place, offender, and potential targets. In the context of Material Handling, the three elements of crime are mentioned as Man, Machine, and Environment. This is seen as a form of interaction that occurs between workers as controllers and potential actors with production equipment or raw materials as potential targets and where the production process is carried out in Material Handling. So, the results of the analysis of these concepts will find out how the Material Handling system that is applied in the production process that they do can have a role to prevent the internal occurrence of Theft in terms of policy makers in the realm of production as a Controller. 


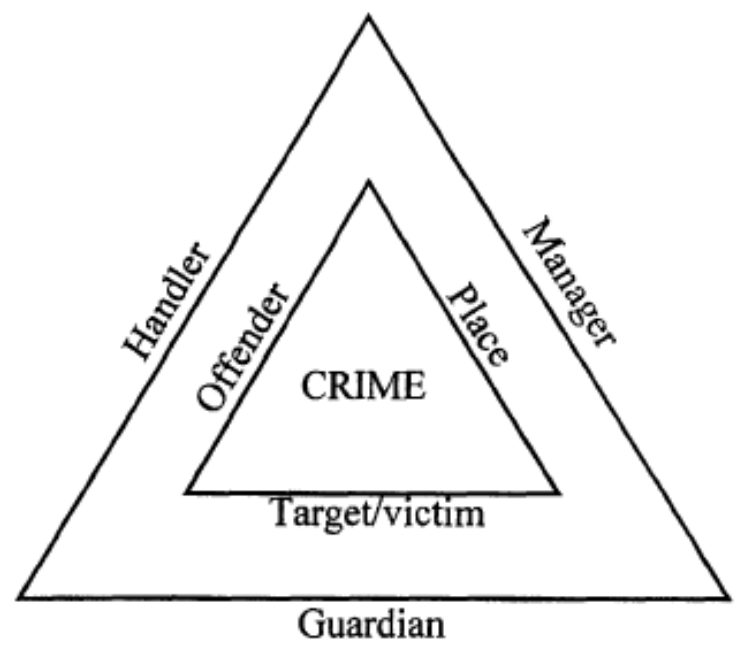

Fig. 3. Problem Triangle Analysis by Eck

The following question arises is this complex nature of the manufacturing industry a weakness or even a strength in the face of Internal Theft? The complexity of the process carried out in the production of the manufacturing industry presents new problems. Based on these characteristics, manufacturing industry companies have their challenges in detecting and investigating crimes such as theft of production and material, which crimes cannot always be seen with the naked eye but in some instances have caused serious losses [13]. This is due to the long series of production processes in this type of industry, which allows for the discovery of gaps in security efforts that have been made so that there is an opportunity for theft, both for production materials and finished goods. Besides based on the facts of several cases of Internal Theft that occurred, theoretically the selection of materials and raw materials as targets for Internal Theft is not without reason. For targets, four main elements influence the magnitude of risk faced as crime targets [14]. The size of this risk will affect the size of the opportunity for an object to be targeted as a crime. The four elements are:

1) Value, which is the size of the value of a potential target for use or resale

2) Inertia, mass and other physical factors related to target strength in the illegal disappearance process

3) Visibility, easy for the target to be seen and known by potential targets

4) Access, whether there is a legal and illegal entry point at the crime scene

This research will discuss more deeply about the factors that cause internal theft to be one of the threats to economic security from internal aspects. Besides, further, this research will also discuss matters that can generally be done by business actors, especially in the manufacturing industry sector to cr eate conditions of resilience in the industry they live in so that they can run more stable. The thing to emphasize from this research is to support and support the realization of economic resilience in terms of industrial sustainability, it is important to establish resilience from the level of the business itself through awareness of internal threats. Thus from here, we believe that the resilience in the economy and the development of Indonesia's economic strength 
through indicators of the number of business actors in the manufacturing industry must be supported by the ability to analyze and identify the problem of threats from one of them, internal theft.

\section{Methods}

This research uses 2 big methods. First, the literature study method is used to examine in more depth the methods that have been used to identify and overcome the occurrence of internal theft in various types of businesses and manufacturing industries. Furthermore, to produce recommendations that can be applied based on the context of the manufacturing industry in Indonesia, a field analysis is carried out on one type of manufacturing industry. Field analysis is done by conducting interviews and observations to get in-depth information, especially regarding the material handling system that is applied to a manufacturing industry company. We chose one of the manufacturing industry company in Indonesia in the field of textiles and footwear. This company was chosen because of its status which is a local ownership company with a medium production scale. Several cases of internal theft that occur in this company provide an illustration of how medium manufacturing industry companies are able to identify internal theft threat and how to overcome it through intervention in material handlings system. From this stage, we gather information on how local owned manufacturing industry use material handlings system as a tool to prevent internal theft and minimize the threat and risks.

The two methods used will then be re-analyzed to form a formula and recommendations that can be applied by manufacturing industry players to form resilience conditions in their respective fields of industry. Not only consider the security aspects in increasing the ability to identify and handle the occurrence of internal theft, however, efforts taken to achieve this must also be aligned and appropriate with the principles held by the manufacturing industry. Also, proving that to improve efficiency, local manufacturing companies that are still in the small and medium scale can use materials handlings as an effort to prevent crime and prevent losses. And this has a positive impact on them to have a greater chance to survive and develop because it reduces the losses arising from internal theft.

\section{Results}

What exactly are Internal Theft's targets for the perpetrators? Why is that considered beneficial? In internal theft, things that are targeted as crimes can consist of raw or raw materials, semi-finished goods or new raw materials that go through several stages of production but have not yet become a product of production, the last of which is the production of industrial plants which are raw materials through all stages of production and has been strictly selected in terms of the quality standards that must be owned by a product.

To make an effort to prevent crime, from the perspective of criminology, several approaches can be used such as physical intervention, the use of supporting devices to the management of human resources in the vicinity of crime locations. In the context of internal theft crimes, the parties with the most potential for committing crimes are employees who have direct access to a variety of assets and devices contained in the manufacturing industry. Having previously mentioned environmental and physical approaches as an effort to prevent crime, another approach that can be applied is the development of human resources. One of the studies 
that talked about the approach to humans in preventing crime, especially in the industrial world and efforts made by Fincy Pellisserry [15]. In his research, Pellisserry stated that now is the time for the company to conduct a system restructuring that places employees as exiled parties by protecting, guaranteeing the quality of life and comfort on the job site. This is done by carrying out management and treatment of employees to make them have no desire or intention to commit crimes with the workplace as their target.

In terms of the efficiency of the implementation of safeguards from the occurrence of internal theft, [10] conduct research that discusses the efficiency of the Material Handling system conducted on ships that have a significant impact on the effectiveness of marine operations. As mentioned earlier, material handling is an important concept and system implemented in the manufacturing industry. The material handling system specifically talks about the ways and steps needed in handling raw materials from one stage to another. What is emphasized in this research is the Material Handling System design which involves workers, tools and existing environmental conditions, where the previous design was judged not to be well integrated, especially to the physical design owned by the ship. Specifically, this research analyzes the operational aspects of the Material Handling system, identifies problems in the logistics system and focuses on optimizing, applying simulation and optimizing theories and methods to the local optimization of the Material Handling system.

The final results obtained by this research are in the form of an index of material accessibility flow evaluation to evaluate the Material Handling system inside the ship and make suggestions for optimization steps to support the overall design. These aspects are analyzed using the theories and methods of Human Factors Engineering and Logistics System Engineering. The results of the analysis carried out on the aspects mentioned earlier yielded two big points. First, is the optimization of the Material Handling system that is being implemented. Second, namely in the form of an evaluation of the Material Handling system. Three things included in the evaluation scope mentioned are security, efficiency, and economy. One of the things related to the discussion in the writing that the researcher is going to develop is about security. More specifically, evaluations related to security include reliable human resources, equipment that can be used properly, the security of the pathways in place, and also the security of storing materials and ammunition. Although the research in this paper is carried out on the Material Handling process in a naval ship, the point taken from this paper is that the attention and development of safeguards in the Material Handling process can be carried out in line with other principles and can also be applied to a manufacturing industrial production system.

Almost in line with research conducted by $\mathrm{Li}$ and Han on the development of security functions in a material handling system, a field study conducted in this research on material handling systems conducted by one of the manufacturing industries in Indonesia also shows the development of material handling systems as a tool to protect assets from the occurrence of internal theft. This is done sequentially from the arrival of production raw materials into the warehouse to the storage of production results. The production process owned by the manufacturing industry covers raw material warehouses, cutting and lamination processes, sewing processes, rubber processing, rubber gluing processes, merging and packaging processes, and finished goods warehouses. Utilization of material handling as an effort to safeguard from internal theft also involves elements in every material handling system, namely man, machine and environment.

In addition to supervising the place as a form of control, management also controls by limiting the area for certain functions or parties that can access the area. One of them is what happened in the area of the Department of Warehouse of Finished Goods. in the previous elaboration on the procedure of producing the products into the warehouse, it was stated that 
this department was divided into several areas. In the area restriction procedure, including the transfer of production results, assist observation and supervision, especially for producing results that are problematic so that the displacement is still in the proper procedure. Here the manager as the party who controls the division of the area must ensure that things are done according to the procedure. Not only in the case of displacement of production, area restrictions for locations that are considered important are also imposed for workers and security officers and expedition vehicles.

Actions taken by the company to potential actors as a form of control begin with actions to facilitate the identification of parties entering the factory or production area. One example of action taken is by requiring to use certain distinguishing identifiers or attributes in the factory area and the production area that is applied differently to employees, guests, and students who are active in the factory area. In the context of Material Handling the identification of this person is very important to see or determine the parties that may or have the authority to access or do something. Not only for individuals, but also for vehicles that are active in the region. Another example that occurs is an entry permit for a vehicle delivering raw materials or the authorities to make a decrease in materials and raw materials sent by the supplier to facilitate supervision and accountability in the process. Ownership of identity cards and delivery documents for materials and raw materials will be very important as a means of verifying that it is true that the person who is supposed to deliver the necessary goods.

After discussing the control carried out by the manager over the party considered as a potential actor, it will then be discussed regarding a more specific matter, namely funding the way taken by the manager in exercising control over potential actors at other production points. Control at this point control is mostly done at points with a high asset or target values. Like the one that happened at the Goods Warehouse. The control taken by this authority is related to one of the control efforts taken by the Manager of the place. Workers or other parties who have interests or in certain positions will influence the policies that will be imposed on him regarding the permissibility to access an area that has been carried out by the Manager in a location. Certain procedures must be passed by people outside the Warehouse Staff if they are going to enter the area. The provisions include having to go through permission from the Head of the Finished Goods Warehouse which will then be forwarded to the security officer in charge, filling in and out of visitors to the Warehouse, to prohibit unauthorized parties from entering the area. In this case, the Head of the Warehouse as the manager conducts supervision by applying for a centralized permit only on his part to provide access for those who will access the location. Hopefully, this will further narrow the possibility of unauthorized parties entering and away from opportunities for irresponsible action.

Furthermore, the object referred to as the most vulnerable to being targeted for crime is processed goods both in the form of raw materials and materials that have not been processed until they have been produced. In Material Handling in the production process, steps for handling materials and raw materials to become a product of production are important because they have to consider various aspects such as economics, efficiency, and guaranteed quality.

In the Finished Goods Warehouse, the value of the function and nominal production results become more and more influenced by the packaging process, including the provision of brand tags and price tags as well as other equipment. This is what makes the company make a special effort throughout the production process to maintain the production assets owned and enforce different rules at points that are considered to have higher asset values than other points and increase supervision efforts at that point. The actions taken against their potential targets have several objectives to be met, namely efficiency, quality assurance, and quality. Material Handling actions taken and can prevent the occurrence of Internal Theft is the inventory of 
materials and raw materials. This can be seen from the data input activity for materials and raw materials that will enter the Raw Material Warehouse. Monitoring the type and amount of materials and incoming raw materials are also monitored from the standard material requirements that are known based on the formula of raw materials that have been developed by multiplying the number of shoes to be produced.

In the manufacturing industry, efficient use of materials and raw materials for the production process is very important to do. As a step taken to achieve the efficient level of use of materials and raw materials, the procedure for the existence of standards for material needs has another role, namely that it can also monitor the amount of material and raw material inventory in the Raw Material Warehouse. Here, the parties responsible for each production process work together with other divisions and also the Head of the Raw Material Warehouse performs its function by implementing a system that is applied to potential targets, namely materials and raw materials so that both quality and quantity can be integrated. This is due to the need for materials and raw materials required precise data. With the right inventory data, the distribution of materials and raw materials can certainly run smoothly and monitoring the quantity of inventory can be done continuously. Not only for the sake of production, but also for other company needs such as payment processing or product development and evaluation.

Furthermore, data collection and control measures against potential targets are again carried out with strict supervision and procedures after the materials and raw materials have been produced and produce finished goods. The results of the production of these shoes begin to be given more attention when entering the packaging or packing. From the Packing section three scans will be carried out into different databases, namely reports on the number of final products that have entered the Packing section, reports on the amount of production that has been issued by Packing to enter the Finished Goods Warehouse, and finally the scanning of production results. conducted and entered into the Material Warehouse. The latest data is data that is used as a list of inventory results that are ready to be distributed.

Controlling efforts carried out by the Guardian on production results as potential targets contained in the Material Handling system has a role and function almost the same as that carried out on materials and raw materials. The scanning procedure as a data collection on production results can also be seen as a control function of production results. The number or target of production that has been determined before the start of the production process is a guideline for the amount of production that should have been entered into the Finished Goods Warehouse. Other than that, of course, the procedure can monitor the amount of production that has been distributed to the market and become revenue for the company. The scanning system as a means of monitoring the inventory of products is strengthened by the existence of Stock Holding which is done every three months. Stocktaking or checking an inventory is done every 3 months based on physical availability. This makes the Internal Theft action which is used as a discussion in this study can be prevented or can be more quickly detected if there is an inventory taking of finished goods outside the predetermined procedure. In this case, the existence of Stock Taking is one of the methods in the Material Handling system that is used by managers to monitor and avoid potential targets for transactions outside the company's requirements. It does not stop there, in addition to the scanning system applied to the entry and exit of products, the Finished Goods Warehouse also applies the zoning system for storing production results based on product categories and sales targets. Therefore, the flow of goods can be monitored more systematically and in detail. 


\section{Discussion}

\subsection{Analyzing Material Handling: An Alternative Strategy to Prevent Internal Theft for Small and Medium Manufacturing Industry}

Although the safe conditions of internal threats are very important, it must be recognized that the actions needed to realize these conditions both physically and in the construction of the system require no significant cost burden. As in terms of interventions that are needed physically or environmentally, the purchase of surveillance cameras and detection devices as surveillance devices. The burden of costs incurred for the purchase of the device must also be followed by maintenance costs, repair costs and costs that need to be prepared for the replacement of damaged units. Apart from the physical intervention through devices, prevention of internal theft also needs to be done in terms of building a system. This system was formed and operated as the main driver for preventing internal theft, which is supported by the device that was mentioned earlier.

The various considerations above cause the identification capabilities possessed by business actors in assessing the condition of their vulnerability to the occurrence of internal theft tends to be low. this is evidenced by studies conducted by the research institute Ernst and Young regarding the level of the company's ability to identify the presence or absence of internal threats owned by the company shows that 31 of the companies thought they did not have enough effective ways to evaluate the weaknesses of the system, even $28 \%$ from companies is less than enough to detect that their system is in danger.

So, from the description of the conditions regarding security and the principles held by the manufacturing industry, what steps can carry out the security function in prevention, but still in line with the principle of efficiency which is emphasized in the manufacturing industry?

From a brief description of materials handling, it can be seen that the focus of manufacturing industry management is on the effectiveness of production, both in terms of energy, resources, land, and also costs. Material Handling does not specifically make the safety factor one of the elements contained in it. In fact, by making Material Handling one of the efforts in preventing Internal Theft, the efficiency of decision making regarding the system to be implemented by a company can be greatly helped. The efficiency of the factors of production has a very important role for the company, where the company expects the maximum possible profit by issuing or using the minimum production costs, including in the Material Handling process [18]. Material Handling can also be analyzed as one of the safeguards and has a role in preventing the prevention of Internal Theft crime in a production process. Although purely Material Handling does not directly place security points in it, now the development of a study of the linkage of Material Handling with security continues. The safety aspect analysis in Material Handling which is carried out in a series of manufacturing industry production processes is carried out using the crime triangle as an analysis tool for the Material Handling system that is carried out. Research from $\mathrm{Li}$ and Hang shows that a focus on security in the Material Handling process does not interfere with efficiency and economic value in a system that is applied. It was even stated that it was an evaluation of the performance of a Material Handling system that was implemented to align human resources and tool resources with the system as a whole so that security, efficiency, and economic conditions were achieved. These are the things that researchers will use to develop this research and link the Material Handling system carried out in a manufacturing industry production with security related to the prevention of Internal Theft crimes. 
Besides, based on field findings there is control over potential targets in the form of materials and raw materials as well as production results in the Material Handling system to prevent the occurrence of Internal Theft is greater in the collection of goods to facilitate monitoring the entry and exit of these potential targets. In other words, Material Handling is not only a system that is implemented in the realm of production but also simultaneously provides a control function that is reflected in the policies and procedures implemented to oversee the entry and exit of goods. Actions taken as a form of control over the place are carried out as observers and narrow the access space for parties outside the authorities. This can be seen from the Material Handling process that is done there are restrictions on access for certain people to be closer to reach access easily, such as positioning departments that are closely related, so that in addition to the travel time of moving goods can remain efficient, monitoring the movement of goods during the occurrence of the production process can still be monitored by the relevant departments. With the result that simultaneously, the efficiency of time and energy in accessing each item of production needs can be met, and the security and supervision functions at the location can also be carried out.

\section{Conclusion}

Basically, to overcome internal theft is an embodiment of the efforts to strengthen the internal of each manufacturing company. Unfortunately, the issue of crime prevention in the realm of the manufacturing industry still seems to be exclusive, especially for small and medium-class manufacturing industries. The stability of the sustainability of a business including the manufacturing industry is influenced by the condition and internal management of a company. Thus, the small and medium scale manufacturing industry can have its resilience so that the industrial business can take place over a long period. Efficiency in efforts to prevent crime through analysis of the Material Handling system that is applied makes the prevention of internal theft even more possible. The implication of this approach is expected to contribute to resilience both at the level of business and the national economy.

\section{References}

[1] R. Pasaribu, Industri dan Industrialisasi, Jakarta: Universitas Gunadarma, 2012.

[2] A. Nasution, Stabilotas Sistem Keuangan: Urgensi, Implikasi Hukum, dan Agenda ke Depan, Jakarta: Kementrian Hukum dan HAM, 2003.

[3] e. a. Robert J. Fischer, Introduction to Security, US: Butterworth-Heinemann, 2011.

[4] D. O. Friedrich, Trusted Criminals: White Collar Crime in Contemporary, Belmont: Wadsworth Cengage Learning, 2010.

[5] J. Bamfield, "Changing Retail, Changing Loss Prevention," Center for Retail Research Journal, 2013.

[6] U. C. o. Commerce, 2011.

[7] T. W. Z. \&. N. M. Scarborough, The essentials of Entrepreneurship and Small Bussiness Management, New Jersey: Pearson Education, 2009.

[8] P. Scallam, Process Planning the Design: Manufacture Interface, Butterworth Heinemann, 2003.

[9] A. Harold, Manufacturing Organization and Management, New Jersey: Prentice-Hall, 1975.

[10] F. L. \&. D. Han, "Study in the Intra-ship Material Handling System," Applied Mechanics and Material, 2013. 
[11] S. L. \&. S. Balbir, "Man-Machine-Environment System Engineering," Proceedings of the 16th International Conference on MMESE, 2016.

[12] S. Ray, Introduction to Material Handling, New Delhi: New Age International Publisher, 2008.

[13] M. L. \&. M. Pulaski, "Fraud and Product Theft Prevention in Industrial Enterprises," Control Engineering Journal, 2014.

[14] R. V. c. Marcus Felson, Opportunity Makes the Thief. Practical Theory for Crime Prevention, London: Research Development Statistic, 1998.

[15] F. Pellisserry, "Corporate Restructuring: Who Cares for The Employees?," Indian Journal of Industrial Relations, pp. 28-35, 2012.

[16] A. J. S. R. \&. D. Sudiadi, Manajemen Sekuriti, Depok: UI Press, 2014.

[17] T. W. Z. \&. Scarborough, The Essentials of Entrepreneurship and Small business Management, New Jersey: Pearson Education, 2009.

[18] J. R. T. Arnold, et al. Introduction to Materials Management Sixth Edition, New Jersey: Pearson Prentice Hall, 2008 